\title{
Composição florística e abundância de pteridófitas em três ambientes da bacia do rio Guamá, Belém, Pará, Brasil.
}

\author{
Silvane Tavares RODRIGUES ${ }^{1}$, Samuel Soares de ALMEIDA², Laíse de Holanda Cavalcante ANDRADE ${ }^{3}$, \\ Iva Carneiro Leão BARROS ${ }^{3}$, Maria Elizabeth VAN DEN BERG ${ }^{2}$
}

\begin{abstract}
RESUMO
Este artigo apresenta os resultados de análise de composição florística, abundância e aspectos fitossociológicos da flora pteridofítica em três ambientes da Área de Pesquisa Ecológica do Rio Guamá, localizada em Belém, PA. Os ambientes estudados foram floresta terra firme (Reserva Mocambo), Floresta de Igapó (Reserva Catu) e a transição entre estes dois ambientes. Em cada sítio foram sorteadas seis parcelas de $5 \mathrm{~m}$ x $10 \mathrm{~m}$. Dentro de cada parcela foram registradas as espécies ocorrentes, contados os indivíduos e anotadas as formas de vida. A flora de pteridófitas inventariada foi de 12 espécies distribuídas em 11 gêneros e nove famílias botânicas. A maior riqueza específica medida foi na área de igapó, seguida da área de transição e de terra firme, embora a de terra firme tenha apresentado maior densidade de indivíduos. Algumas espécies apresentam elevada freqüência e abundância em mais de um hábitat, enquanto outras podem ser localmente raras e restritas a um só ambiente. A floresta de igapó apresentou menor similaridade tanto internamente como quando comparada com a de terra firme e a de transição. As epífitas verdadeiras ou holoepífitas dominaram nos três ambientes estudados, sendo mais representativas no igapó, onde a inundação do solo deve inibir as formas terrestres. Estratégias de proteção para este grupo de plantas devem priorizar unidades de conservação que incluam variação ambiental, uma vez que mesmo ambientes próximos e interligados podem incluir considerável número de espécies exclusivas ou restritas.
\end{abstract}

\section{PALAVRAS-CHAVE}

pteridófitas, Amazônia Brasileira, abundância e composição florística de pteridófitas.

\section{Floristic Composition and abundance of pteridophites in three environments of the Guamá river basin, Belém, Pará, Brazil.}

\begin{abstract}
S
This paper presents of the results of floristic composition, abundance and phytossociological aspects of pteridophytic flora in three environments of the Ecological Research of Rio Guamá Area (APEG), located in Belém, Pará State, Brazil. The studied environments were a dense amazonian lowland, called "terra firme" forest (Mocambo Reserve), a swamp forest, called "igapó" (Catu Reserve) and a transitional area in these two ecosystems. Each of the three environmental sites were divided into six plots of $5 \times 10$, for a total of 18. In each plot species ocurrence was recorded, and all individual plants and life forms counted. The life forms were discriminated into bemi-epiphytes, bolo-epiphytes and terrestrial. The inventoried pteridophytic flora encompassed 12 species distributed into 11 genera and 9 botanical families. The largest diversity was found in the "igapó", followed by transition ecotone and the "terra firme" forest, although the "terra firme" showed more plant abundance. Some species showed high frequency and abundance in more than one habitat, while anothers were locally rare and restricted to only one environment. The "igapó" forest plots present smaller internal similarity when compared with "terra firme" and the transition forest plots. The true epiphytes or holoepiphytes prevailed in all three studied environments, however they were more representative in the igapó forest, where the permanent soil flooding may have inhibited the terrestrial forms. Protection strategies for this plant group should be directed to implementines units of conservation that includes environmental variation, because even those near as well as interlinked areas, may include considerable number of exclusive or restricted species.
\end{abstract}

\section{KEY WORDS}

pteridophytes, Brazilian Amazonia, floristic composition, abundance of ferns.

${ }^{1}$ EMBRAPA Amazônia Oriental, Laboratório de Botânica, Cx. Postal 48, CEP: 66017, Belém, PA.

${ }^{2}$ Museu Paraense Emílio Goeldi/MCT, Coordenação de Botânica, Cx. Postal 399, Belém, PA.

${ }^{3}$ Universidade Federal de Pernambuco, Departamento de Botânica, Av. Prof. Moraes Rego s/nº., Cidade Universitária, 50.670-901, Recife, PE. 


\section{ACTA \\ AMAZONICA}

COMPOSIČ̃̃O FLORÍSTICA E ABUNDÂNCIA DE PTERIDÓFITAS EM TRÊS AMBIENTES DA BACIA DO RIO GUAMÁ, BELÉM, PARÁ.

\section{INTRODUÇÃO}

As pteridófitas constituem um grupo vegetal bem diversificado e distribuído geograficamente, englobando uma riqueza de aproximadamente 10 mil espécies. Deste total, cerca de um terço ocorre nas Américas. A flora brasileira contempla cerca de mil espécies, ou $10 \%$ da flora mundial deste grupo (Windisch, 1990). Além da diversidade considerável, o Brasil abriga um dos centros de endemismos e especiação do continente sul-americano, localizado no domínio da mata atlântica (Windisch, 1990). Este grupo é muito antigo em termos evolutivos, tendo se formado bem antes das angiospermas e gimnospermas. No período carbonífero as pteridófitas eram muito diversas e constituíam grandes florestas, mas atualmente as formas de vida predominantes são ervas terrestres e aquáticas, epífitas e algumas lianas (Smith, 1955; Ribeiro et al. 1999). As formas terrestres predominam no sub-bosque de florestas úmidas e em vegetação de altitude, associadas a solos e formações rochosas.

No Brasil, os trabalhos sobre a diversidade e a ecologia de pteridófitas ainda são poucos, a maioria realizada na Mata Atlântica. Os primeiros trabalhos foram de cunho taxonômico e florístico. Entre os pioneiros, Windisch (1990) destaca aqueles realizados por botânicos europeus como Raddi (1819), Presl (1822) e Schrader (1825), todos trabalhos gerais e localizados no Sudeste do Brasil. No compêndio da Flora Brasiliensis, este grupo recebeu tratamento taxonômico de Spring (apud Martius \& Eichler, 1840), Kuhn (apud Martius \& Eichler, 1884), Sturm (apud Martius \& Eichler 1859) e Baker (apud Martius \& Eichler 1870).

Na Amazônia Biogeográfica, os estudos sobre a ecologia de pteridófitas estão concentrados nos países andinos, onde o clima ameno aliado à elevada umidade e à disponibilidade de bons substratos, favoreceu a diversificação dos fetos. Neste contexto, os estudos são direcionados para as relações entre as espécies e parâmetros do ambiente como solo e clima. A maioria dos estudos na América do Sul é realizada nos Andes do Peru, Colômbia, Bolívia e Equador (Tuomisto et al. 1998; Galeano et al.1998; Kessler 2001).

O levantamento mais abrangente deste grupo na Amazônia Brasileira foi feito na Reserva Florestal Ducke (Manaus, AM), onde Costa et al. (1999) registraram e coletaram 83 espécies, com famílias de grande riqueza específica como Hymenophyllaceae (11 espécies), Lomariopsidaceae e Polypodiaceae (nove espécies cada). Na região de Belém, Rodrigues (1994), com base em dados de coleta e de herbário, listou 38 espécies pertencentes a sete gêneros e 12 famílias. As mais ricas são Dryopteridaceae (10 espécies) e Polypodiaceae (8 espécies).

A riqueza de pteridófitas na região oeste da América do Sul, no entanto, parece ser mais elevada. Kessler (2001) inventariou intensivamente os pisos altitudinais andinos da Bolívia, registrando um total de 755 espécies, a maioria espécies terrestres. Estimativas por extrapolação indicam que este total pode atingir um total próximo de mil espécies. $\mathrm{O}$ autor enfatiza que espécies terrestres possuem maior tendência a ocorrer de forma agregada do que as epifíticas. Como existe uma relação riqueza e a pluviosidade, o autor argumenta que a proteção da diversidade deste grupo só poderá ser assegurada se áreas mais úmidas das florestas andinas forem priorizadas para conservação.

As condições edáficas parecem exercer forte influência sobre a distribuição destas plantas. Tuomisto \& Poulsen (1996) estudaram a distribuição e a abundância de pteridófitas terrestres no oeste da Amazônia, registrando 64 espécies. Foi verificado que grande parte das diferenças na composição florística está correlacionada com as diferenças de solo, mas a distância geográfica entre os sítios parece não influir na similaridade florística.

A distribuição espacial de seis espécies do gêneroAdiantum foi estudada por Tuomisto et al. (1998) em diversas florestas de terra firme na Amazônia Peruana e Equatoriana. A variação dos padrões de distribuição entre sítios pode ser explicada pelo tipo de solo e a concentração de bases trocáveis (Ca, K, P e Mg), mas a variação topográfica parece influir mais nos padrões de heterogeneidade florística verificados dentro dos sítios.

O inventário da flora vascular feito em Choco, uma região de megabiodiversidade na costa pacífica da Colômbia, por Galeano et al. (1998), acusou um dos mais elevados índices de diversidade dos neotrópicos, constatando-se que palmeiras e pteridófitas foram os grupos mais abundantes, embora as formas de vida mais diversas tenham sido ervas e arvoretas do sub-bosque.

As pteridófitas são um grupo vegetal que inclui muitas formas de vida terrestres, epifíticas e aquáticas. No entanto, as florestas de terra firme da Amazônia são relativamente pobres em espécies. O dossel fechado, que proporciona pouca luz ao nível do sub-bosque, e o baixo nível de nutrientes parecem limitar este grupo neste ambiente. Nos ambientes inundáveis de várzea e igapó, a diversidade também é reduzida quando comparada com os ambientes andinos e a Mata Atlântica, provavelmente devido aos efeitos seletivos da inundação.

Este trabalho visa contribuir para o conhecimento da composição florística, similaridade e abundância da flora pteridofítica em ambientes de floresta de terra firme (Reserva Mocambo), floresta de igapó (Reserva Catu), permanentemente inundada e floresta de transição ou contato entre terra firme e igapó.

\section{MATERIAL E MÉTODOS}

\section{Áreas de estudo}

Todas as trêsáreas onde foram realizados os estudos pertencem ao complexo da APEG (Área de Pesquisa Ecológica do Guamá), pertencente a EMBRAPAAmazônia Oriental, município de Belém, Pará (coordenadas aproximadas: $1^{\circ} 28^{\prime} 7 \mathrm{~S}, 48^{\circ} 27^{\prime} \mathrm{W}$ ).

a) Terra firme: Á área de terra firme fica localizada na Reserva do Mocambo, um fragmento de floresta densa de terra firme de aproximadamente 6 hectares $\left(60.000 \mathrm{~m}^{2}\right)$. O solo desta área é do grupo oxissolo, tipo Latossolo Amarelo 


\section{ACTA \\ AMAZONICA}

COMPOSIÇÃO FLORÍSTICA E ABUNDÂNCIA DE PTERIDÓFITAS EM TRÊS AMBIENTES DA BACIA DO RIO GUAMÁ, BELÉM, PARÁ. textura areno-argilosa. O relevo é relativamente plano e o terreno é do quaternário superior. As principais espécies de árvores neste ambiente são o acapu (Vouacapoua americana Aubl., Caesalpiniaceae), mata-matá branco (Escbweilera coriacea (DC.) Mart. ex Berg., Lecythidaceae), jatereua (Lecythis idatimon Aubl., Lecythidaceae), quaruba branca (Vochysia guianensis Aubl., Vochysiaceae) dentre outras.

b) Igapó: A floresta de igapó do Catu é permanentemente inundada e está sob influência do sistema hídrico do Lago Água Preta, pertencente ao manancial do Complexo Utinga, um dos mananciais que abastecem Belém com água potável. A área do igapó associada aos estudos da APEG tem aproximadamente 4,8 hectares $\left(48.000 \mathrm{~m}^{2}\right)$. Os solos deste igapó são hidromórficos do tipo glei pouco húmico, também de origem quaternária. A característica mais marcante que separa o igapó da terra firme, além do regime de inundação permanente, é o maior espaçamento entre as árvores, e a conseqüente maior abertura do dossel florestal. Entre as espécies arbóreas mais abundantes neste ambiente destacamse o anani (Symphonia globulifera L., Clusiaceae), açaí (Euterpe oleracea Mart., Arecaceae) e anoerá (Licania macrophylla Benth., Chrysobalanaceae).

c) Transição ou contato entre floresta de terra firme e igapó: Este ecótono apresenta-se diferenciado topograficamente, havendo um desnível de 1-2 m entre o platô de terra firme do Mocambo e a porção mais rebaixada do igapó. Este ambiente possui mais luz do que a floresta densa, com maior umidade do solo, porém não está submerso como o igapó. Isto pode favorecer a colonização por espécies de pteridófitas terrestres que necessitem de maiores níveis de luz e umidade. As espécies florestais são mistas entre os dois ambientes, destacando-se o açaí, andiroba (Carapa guianensis Aubl., Meliaceae) e a paxiúba (Socratea exorrbiza (Mart.) H. Wendl., Arecaceae).

\section{Amostragem das pteridófitas}

Foram delimitadas 18 parcelas de $5 \times 10 \mathrm{~m}\left(50 \mathrm{~m}^{2}\right)$, sendo seis na floresta de terra firme do Mocambo, seis na floresta de igapó do Catu e seis na transição entre esses ambientes.

O método de sorteio das parcelas seguiu as técnicas de aleatorização estratificada, recomendada por Moore \& Chapman (1976). Dentro de cada parcela foram registradas todas as espécies e contados os indivíduos de pteridófitas, para obtenção dos parâmetros fitossociológicos de freqüência e abundância.

Durante a fase de levantamento foi anotada a forma de vida de cada planta, com base nos conceitos emitidos por de La Sota (1971) a seguir:

Terrestre: Aquelas plantas com crescimento e sustentação independente, crescendo a partir do solo.

Holoepífita: Aquelas que se fixam sobre outras plantas (forófitos) ou rochas (rupícolas), ali desenvolvendo todo seu ciclo de vida, inclusive retirando da superfície do forófito os nutrientes e água necessários para a sua manutenção.
Hemiepífita: Aquelas que se fixam sobre outras plantas mas que retiram os nutrientes e água do solo.

O sistema de classificação usado para nominar e listar os táxons está de acordo com o proposto por Tryon \& Tryon (1982).

\section{Parâmetros fitossociológicos e análises de riqueza e de similaridade}

Foram calculados os parâmetros fitossociológicos Abundância Absoluta (Ab_A), Relativa (Ab_R, em \%), Freqüência Absoluta (Fr_A) e Relativa (Fr_R, em \%).

Para o cálculo das abundâncias e freqüências relativas (em \%), utilizaram-se as seguintes fórmulas, segundo Mueller-Dambois e Ellenberg (1974):

$$
\begin{gathered}
\mathrm{Ab}_{-} \mathrm{R}=\frac{\mathrm{N}^{\mathrm{o}} \text {.de indivíduos da enésima espécie }}{\mathrm{N}^{\mathrm{o}} \text {. total de indivíduos } .100} \\
\mathrm{Fr} \mathrm{R}=\frac{\mathrm{N}^{\mathrm{o}} \text {. de parcelas em que ocorre a enésima espécie }}{\begin{array}{r}
\mathrm{N}^{\mathrm{o}} \text {. total de parcelas nas quais } \\
\text { ocorreram todas as espécies. } 100
\end{array}}
\end{gathered}
$$

Para as espécies reptantes cada colônia (genet) foi considerada um indivíduo.

Para determinar o índice de riqueza das espécies, foi utilizado o modelo desenvolvido por Margalef (apud Santos 1988):

$$
\begin{gathered}
I_{D}=(S-1) \cdot 0,4343 / \log _{10} N \\
I_{D}=\text { índice de riqueza de Margalef }
\end{gathered}
$$

Onde: $S=N^{\circ}$. de espécies presentes no ambiente

$\log _{10} \mathrm{~N}=$ logarítimo (base 10 ) do número de indivíduos presentes no ambiente.

Para a análise de similaridade os ambientes foram comparados entre si, verificando-se também a variação de similaridade entre parcelas de um mesmo ambiente. Para isto foram separados aleatoriamente dois grupos de três parcelas por ambiente e feita a comparação.

A análise de similaridade florística entre os ambientes foi feita através do Índice de Sorensen (I), segundo Moore \& Chapman (1976).

$$
I_{s}=2 c \cdot 100 / a+b
$$

Onde:

$\mathrm{a}=$ número de espécies presentes no ambiente $\mathrm{A}$.

$\mathrm{b}=$ número de espécies presentes no ambiente $\mathrm{B}$.

$\mathrm{c}=$ número de espécies comuns aos ambientes $\mathrm{A}$ e $\mathrm{B}$.

O sistema de classificação adotado para as pteridófitas foi aquele consignado no tratamento sistemático feito para o grupo por Tryon \& Tryon (1982). 


\section{ACTA AMAZONICA}

COMPOSIČ̃̃O FLORÍSTICA E ABUNDÂNCIA DE PTERIDÓFITAS EM TRÊS AMBIENTES DA BACIA DO RIO GUAMÁ, BELÉM, PARÁ.

\section{RESULTADOS E DISCUSSÃO}

A Tabela 1 apresenta alguns dados florísticos e fitossociológicos dos três ambientes estudados. As abundâncias ou densidades foram estimadas para 1 hectare a partir dos $300 \mathrm{~m}^{2}$ amostrados por ambiente (seis parcelas de $10 \mathrm{~m} \times 50 \mathrm{~m}$ ). O Anexo I contém a listagem geral das espécies de pteridófitas registradas nos três ambientes da bacia do rio Guamá, citadas por Rodrigues (1994) e levantadas nos herbários e literatura afim.

\section{Abundância e riqueza de espécies dos ambientes}

$\mathrm{O}$ ambiente de terra firme foi aquele que apresentou maior densidade de pteridófitas, com 5 mil indivíduos por hectare. $\mathrm{O}$ igapó também apresentou uma densidade elevada, com 4.467 indivíduos. A floresta de transição entre a terra firme e o igapó incluiu um número bem menor de indivíduos, representando apenas $20 \%$ da densidade verificada no ambiente de terra firme.

Com relação à diversidade de pteridófitas, foram registradas 12 espécies nos ambientes estudados, distribuídas em nove famílias botânicas. A transição terra firme-igapó apresentou maior riqueza específica inventariada (nove espécies, $75 \%$ do total), seguida do igapó (oito espécies, 66,67\%) e por último, com poucas espécies, a terra firme (cinco espécies, 41,67\%). O número de famílias seguiu a mesma tendência das espécies, com o ambiente de transição incluindo mais famílias, seguido do igapó e da terra firme. A transição apresentou três espécies exclusivas ou restritas a este ambiente e o igapó duas. A terra firme não apresentou nenhuma espécie cuja distribuição seja restrita a ela, compartilhando com os outros ambientes todas as suas espécies (Tabela 1). Comparando-se as espécies encontradas neste trabalho com as 38 listadas por Rodrigues (1994) para todos os ambientes da APEG, constata-se que somente $30 \%$ foram detectados na amostragem, não obstante a lista de Rodrigues (1994) incluir o ambiente de várzea, que não foi contemplado no presente estudo. Desta forma a listagem de fetos da APEG corresponde a 13,6 \% riqueza específica total indicada por Tryon \& Conant (1975) para a região amazônica.

A riqueza de espécies, medida em decits $\left(\log _{10}\right)$ pelo Índice de Margalef, apontou maior valor para o ambiente de igapó $(2,02)$, seguido da transição $(1,63)$ e a terra firme $(0,80)$. Apesar de apresentar menor número de espécies do que a transição, o igapó apresentou maior riqueza, provavelmente devido à razão entre o número de indivíduos e de espécies ser maior. Young \& León (1989) estudaram a diversidade de espécies de pteridófitas na Amazônia Peruviana e encontraram em suas amostras 24 espécies, distribuídas em solo argiloso e arenoso. Utilizando os dados apresentados pelos autores (número de espécies e de indivíduos), calculou-se o índice de diversidade de espécies na área por eles estudada, verificando-se que a riqueza florística foi maior em solo argiloso $(3,03)$ do que em arenoso $(2,17)$ e que este último valor aproxima-se do obtido para a floresta de igapó.

\section{Similaridade dentro e entre os ambientes}

Os índices de similaridade das espécies ocorrentes na mata de terra firme, mata de contato entre os dois ecossistemas e mata de igapó constam da Tabela 2.

A similaridade florística entre grupos de parcelas de um mesmo ambiente é maior quando comparada àquela verificada para os grupos de parcelas de ambientes distintos (Tabela 2). Todas elas compartilham pelo menos $50 \%$ da similaridade explicada pelo índice, entretanto a similaridade florística entre grupos de parcelas de um mesmo ambiente é maior quando comparada àquela verificada para os grupos de parcelas de ambientes distintos. As parcelas de floresta de terra firme são mais semelhantes floristicamente entre si (75\%), do que aquelas inventariadas em áreas de transição $(71,4 \%)$ e de igapó $(54,5 \%)$ (Tabela 2). Isto sugere que a floresta de terra firme

Tabela 2 - Porcentagens de similaridade florística de Sørensen nos ambientes inventariados. APEG, Belém, Pará. Legendas: FTF Floresta de terra firme, FC - Floresta de contato ou transição e FI - Floresta de igapó. Em negrito o cruzamento de índices entre parcelas de um mesmo ambiente.

\begin{tabular}{lllllll}
\hline \hline Ambientes & $\mathrm{FTF}_{1}$ & $\mathrm{FTF}_{2}$ & $\mathrm{FC}_{1}$ & $\mathrm{FC}_{2}$ & $\mathrm{FI}_{1}$ & $\mathrm{FI}_{2}$ \\
\hline $\mathrm{FTF}_{1}$ & 100,0 & & & & & \\
$\mathrm{FTF}_{2}$ & 75,0 & 100,0 & & & & \\
$\mathrm{FC}_{1}$ & 50,0 & 60,0 & 100,0 & & & \\
$\mathrm{FC}_{2}$ & 50,0 & 57,1 & 71,4 & 100,0 & & \\
$\mathrm{Fl}_{1}$ & 28,5 & 66,6 & 44,4 & 46,1 & 100,0 & \\
$\mathrm{FI}_{2}$ & 40,0 & 50,0 & 33,3 & 50,0 & 54,5 & 100,0 \\
\hline \hline
\end{tabular}

Tabela 1 - Sumário da abundância e riqueza da flora pteridofítica estudada nos ambientes de floresta de terra firme, floresta de igapó e contato/transição. Área de Pesquisa Ecológica do Guamá (APEG), Belém, Pará.

\begin{tabular}{|c|c|c|c|c|c|}
\hline \multirow{2}{*}{ Ambientes } & \multirow{2}{*}{$\begin{array}{c}\text { Densidade } \\
\text { por ha }\end{array}$} & \multicolumn{2}{|c|}{ No. de Espécies } & \multirow{2}{*}{$\begin{array}{l}\text { No. de } \\
\text { Famílias }\end{array}$} & \multirow{2}{*}{$\begin{array}{c}\text { Índice Riqueza } \\
\text { Margalef }\end{array}$} \\
\hline & & Total & Exclusivas & & \\
\hline Terra firme & 5.000 & 5 & 0 & 5 & 0,80 \\
\hline Igapó & 4.467 & 8 & 2 & 6 & 2,02 \\
\hline Transição/Contato & 1.067 & 9 & 3 & 8 & 1,63 \\
\hline Média ou Total & 2.634 & 12 & - & 9 & - \\
\hline
\end{tabular}




\section{ACTA \\ AMAZONICA}

COMPOSIÇÃO FLORÍSTICA E ABUNDÂNCIA DE PTERIDÓFITAS EM TRÊS AMBIENTES DA BACIA DO RIO GUAMÁ, BELÉM, PARÁ. possa ser mais uniforme em termos físicos, e que maior variação ambiental possa ocorrer no igapó, onde níveis de inundação e luz e a variação topográfica podem controlar as diferenças florísticas.

As maiores dissimilaridades ocorrem entre o primeiro grupo de parcelas de terra firme e o igapó (28,5 e 40,0\%), e entre o primeiro grupo de parcelas da transição e o igapó (44,4 \% e 33,3 \%) (Tabela 2). Estes resultados indicam que a floresta de igapó, além de variar mais internamente, também varia bastante em relação aos demais ambientes (Tabela 2).

\section{Composição florística e análise fitossociológica}

A Tabela 3 apresenta o resultado da análise fitossociológica realizada nos três ambientes estudados.

\section{Freqüência}

As 12 espécies inventariadas estão distribuídas em 11 gêneros. Destes, apenas o gênero Microgramma apresenta duas espécies. A espécie M. lindbergii ocorre somente no igapó com abundância baixa, enquanto $M$. tecta está presente nos três ambientes. Entre as nove famílias detectadas, Hymenophyllaceae, Vittariaceae e Polypodiaceae incluíram duas espécies cada e o restante apenas uma espécie.

Algumas espécies estão em todos os ambientes e distribuídas em muitas parcelas como Asplenium serratum, que ocorre em $14(77,78 \%)$ das 18 parcelas; inventariadas; Antrophyum cajenense e Hecistopteris pumila, estão presentes em sete $(38,89 \%)$ parcelas, indicando maior tolerância ambiental ou nicho ecológico mais amplo. $A$. serratum é a espécie mais freqüente na terra firme $(35,71 \%)$ e na transição com o igapó (21,05\%), indicando certa preferência por ambientes menos úmidos e sombreados, enquanto $A$. cajenense mais freqüente no igapó (40,00\%), sendo provavelmente, uma espécie indicadora de ambiente mais saturado de água e com maior luminosidade (Tabela 3).

Em contraste às espécies de ocorrência irrestrita, existem aquelas que estavam presentes numa só parcela de um único ambiente como Microgramma lindenbergii, Lindsaea lancea, restritas do igapó e Danaea simplicifolia, com ocorrência exclusiva à transição terra firme-igapó. Trichomanes vittaria e Adiantum cajennense também são espécies restritas à transição mas aparecem em duas parcelas (freqüência de 10,53\%) e três parcelas (15,79\%), respectivamente (Tabela 3).

Em alguns casos as espécies também estavam presentes em dois ambientes, indicando certo grau

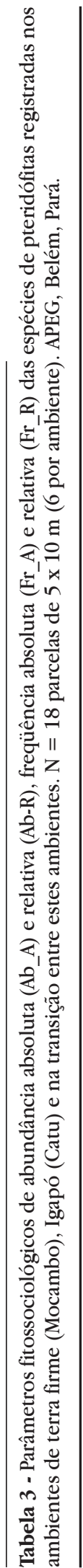




\section{ACTA \\ AMAZONICA}

COMPOSIČ̃̃O FLORÍSTICA E ABUNDÂNCIA DE PTERIDÓFITAS EM TRÊS AMBIENTES DA BACIA DO RIO GUAMÁ, BELÉM, PARÁ. de tolerância à variação ambiental. Além de A. cajenenense, Triplophyllum funestum é outra espécie presente nos ambientes de transição e igapó, denotando tendência a preferir locais mais úmidos, enquanto Selaginella amazonica foi registrada na terra firme e na transição, sugerindo que vegeta melhor em locais mais altos e com menor umidade. No caso de Hymenophyllum polyanthos, que está presente na terra firme e no igapó, é bem provável que também ocorra no ecótono de transição (Tabela 3).

\section{Abundância}

As pteridófitas com forma de vida terrestre possuem tendência a apresentar populações agregadas, a exemplo do que já foi constatado por Kessler (2001) nas florestas andinas da Bolívia. Isto pode ser observado através da abundância de algumas espécies como Selaginella amazonica, representada por $42,67 \%$ de todos os indivíduos das espécies registradas na terra firme. Na transição, a espécie mais abundante foi Hecistopteris pumila, cuja abundância de 39,55 \% esteve fortemente concentrada somente em duas parcelas (10,53 $\%)$. No igapó, Antrophyum cajenense foi a espécie mais abundante (40,63\%), embora seus indivíduos estivessem ocorrendo em todas as parcelas deste ambiente (Tabela 3).

Cain et al. (1956) fizeram um levantamento das espécies de Angiospermas presentes em dois hectares da Reserva Mocambo. Encontraram 173 espécies de árvores, a maioria em baixa freqüência. Constataram ainda, de modo muito evidente, uma freqüência relativa baixa da maioria das espécies. $\mathrm{O}$ mesmo foi observado neste trabalho com relação às pteridófitas, pois a maioria das espécies ocorrentes nas parcelas analisadas nas Reservas Mocambo e Catu apresenta freqüência rara.

A existência de espécies pouco abundantes pode indicar raridade local, mas os resultados muitas vezes devem ser analisados com cautela, porque podem ser produto de amostragem insuficiente para detectar a escala espacial em que determinadas espécies ocorrem. A despeito dessas considerações, a espécie Microgramma tecta, apesar de ocorrer nos três ambientes, em todos eles aparece com poucos indivíduos e distribuída num número reduzido de parcelas (Tabela 3 ).

Algumas espécies apresentaram padrão misto de abundância, com numerosos indivíduos num local e com poucos em outros. Isto pode ser exemplificado por Selaginella amazonica, abundante na terra firme, mas relativamente rara na transição e ausente no igapó. Antrophyum cajenense é relativamente abundante no igapó, rara na transição e ausente na terra firme. Asplenium serratum é uma espécie relativamente abundante na terra firme e na transição, mas rara no igapó (Tabela 3).

\section{Distribuição de formas de vida entre os ambientes}

As formas de vida ou hábito vegetativo das pteridófitas inventariadas estão representadas na Tabela 4 .

$\mathrm{Na}$ floresta de terra firme, as formas de vida predominantes estão divididas entre as ervas terrestres e as holoepífitas, com freqüências alcançando 44,67\% e 53,33\% entre os indivíduos amostrados, respectivamente. Este resultado indica que o solo é um substrato razoável neste ambiente e que metade das plantas estão usando os recursos minerais e a água do solo para se manter. A outra metade se mantém com os nutrientes e água disponíveis nos troncos e galhos de seus hospedeiros. Na floresta de igapó, a dominância das holoepífitas é mais significativa, incluindo 84,38 \% de todos os indivíduos registrados (Tabela 4). Parece que as condições terrestres do igapó não são muito favoráveis ao desenvolvimento das pteridófitas, possivelmente devido ao longo período de inundação. Este mesmo padrão se repete na transição entre o igapó e a terra firme onde 66,6 \% dos indivíduos são holoepífitos e 32,5\% terrestres (Tabela 4).

Se forem considerados os dois grupos de epífitas (holo e hemiepífitas), verifica-se que os resultados estão de acordo com os de Pires (1973), para o qual as epífitas são mais abundantes nas florestas densas, tipo em que se enquadra a Reserva do Mocambo, sendo escassas apenas nas matas de cipó, embora a diversidade neste último ambiente seja maior.

\section{CONCLUSÕES}

As pteridófitas apresentam abundâncias e freqüências diferenciadas dentro e entre os ambientes estudados, sendo em geral mais numerosas e freqüentes na floresta de terra firme, seguida da floresta de transição e do igapó. No entanto, o igapó é o ambiente mais rico e com maior número de espécies exclusivas.

A floresta de igapó apresenta maior heterogeneidade interna e também é mais dissimilar quando comparada com a transição e a terra firme. As epífitas sensu stricto (holo-epífitas) são mais freqüentes em todos os ambientes estudados.

Tabela 4 - Formas de vida das pteridófitas inventariadas nas florestas de terra firme, igapó e transição. APEG, Belém, Pará.

\begin{tabular}{lcccccc}
\hline \hline \multirow{2}{*}{ Forma de Vida } & \multicolumn{2}{c}{ Terra Firme } & \multicolumn{2}{c}{ Transição } & \multicolumn{2}{c}{ Igapó } \\
\cline { 2 - 7 } & No. de Indivíduos & $\%$ & No. de Indivíduos & $\%$ & No. de Indivíduos & $\%$ \\
\hline Terrestre & 67 & 44,67 & 43 & 32,09 & 5 & 15,63 \\
Holoepifítas & 83 & 55,33 & 88 & 65,67 & 27 & 0 \\
Hemiepifítas & 0 & 0,00 & 34,38 & 0,00 \\
\hline Total & 150 & 100,00 & 134 & 100,00 & 32 & 100,00 \\
\hline \hline
\end{tabular}




\section{ACTA \\ AMAZONICA}

COMPOSIÇÃO FLORÍSTICA E ABUNDÂNCIA DE PTERIDÓFITAS EM TRÊS AMBIENTES DA BACIA DO RIO GUAMÁ, BELÉM, PARÁ.
A flora de pteridófitas inventariada nos três ambientes da APEG é relativamente pobre, embora seja complementar às floras inventariadas em outros locais da região.

Estratégias de proteção para este grupo de plantas devem priorizar as unidades de conservação que incluam variação ambiental, uma vez que mesmo ambientes próximos e interligados podem incluir considerável número de espécies exclusivas ou restritas.

\section{BIBLIOGRAFIA CITADA}

Cain, S.A.; Castro, G.M.O.; Pires, J.M. 1956. Composition and structure of terra firme rain forest at Mocambo, Belém, Pará. American Journal of Botany, 43: 915-941.

Costa, M.A.S.; Prado, J.; Windisch, P.; Freitas, C.A.A.; Labiak, P. 1999. Pteridophyta. In: Ribeiro, J.E.L.; Hopkins, M.J.G.; Vicentini, A.; Sothers, C.A.; Costa, M.A.S.; Brito, J.M.; Souza, M.A.; Martins, L.H.; Lohmann, L.G.; Assunção, P.A.C.L.; Pereira, E.C.; Silva, C.F.; Procópio, L.C. Flora da Reserva Ducke - Guia de identificação das plantas vasculares de uma floresta de terra firme na Amazônia Central. Instituto Nacional de Pesquisas da Amazônia, Manaus, Amazonas, p. 97-117.

De La Sota, E.R. 1971. El epifitismo y las Pteridófitas en Costa Rica (América Central). Nova Hedwigia, 21 (1-4): 401-465.

Galeano, G.; Suarez, S.; Balslev, H. 1998. Vascular plant species count in a wet forest in the Choco area on the Pacific coast of Colombia. Biodiversity and Conservation, 7(12): 1563-1575.

Kessler, M. 2001. Pteridophyte species richness in Andean forests in Bolivia. Biodiversity and Conservation, 10 (9): 1473-1495.

Martius, C.F.P.; Eichler, A.G. (ed.). 1840-1884. Flora Brasiliensis. Lipsiae apud Frid. Fleicher in Comm. Monochii.

Moore, P.D.; Chapman, S.B. 1976. Methods in Plant Ecology. Oxford: Scientific Publications, 589pp.

Mueller-Dambois, D.; Ellenberg, H. 1974. Aims and Methods in Plant Ecology. New York, John Willey and Sous (ed.) p. 45 - 135
Pires, J.M. 1973. Os tipos de vegetação que ocorrem na Amazônia. Simpósio sobre a Biota Amazônica de 1966. Pub. Avulsas, n.20, MPEG.

Presl, K. 1822. Plantarum novarum Brasiliae presertim Filicum Linnei diagnoses et descritptiones. Delicieae Pragenses. Prag., 158-190.

Raddi, J. 1819. Synopsis filicum brasiliensium. Opusc. Sci. Bol., 3: $279-297$.

Rodrigues, S.T. 1994. Flora pteridofítica de três ecossistemas sob influência do rio Guamá (Pará-Brasil). Master's Thesis, Universidade Federal de Pernambuco, Recife, 134pp.

Santos, E.J. 1988. Sistemática e ecologia de Myxomycetes ocorrentes em cana-de-açúcar (Sacharum sp). Master's Thesis, Universidade Federal de Pernambuco, Recife, 198pp.

Schrader, H.A. 1825. Illustratio Filicum a Serenissimo Principe Neovidensi in Brasilia observatarum, Gottinger Gel. Anz:: 857-872.

Smith, G.M. 1955. Botânica Criptogâmica, volume II- Briófitos e Pteridófitos. Fundação Calouste Gulbenkian, Lisboa, 386pp.

Tryon, R.M.; Conant, D.S. 1975. The ferns of Brazilian Amazonia. Acta Amazonica, 5 (1): 23-34.

Tryon, R.M.; Tryon, A.F. 1982. Ferns and allied plants with special reference to Tropical America. Springer-Verlag, New York, 857pp.

Tuomisto, H.; Poulsen, A. D. 1996. Influence of edaphic specialization on pteridophyte distribution in neotropical forests. Journal of Biogeography 232 (3): 283-293.

Tuomisto, H.; Pousen, A. D.; Moran, R.C. 1998. Edaphic distribution of some species of the fern genus Adiantum in western Amazonia. Biotropica, 30 (3): 392-399.

Windisch, P.G. 1990. Pteridófitas da região Norte-Ocidental do Estado de São Paulo: Guia para estudo e excursão. São José do Rio Preto: UNESP, 108pp.

Young, K.R.; Léon, B. 1989. Pteridophyte species diversity in the central peruvian amazon: importance of edaphic specialization. Brittonia, 41(4): 388-395.

\section{ANEXO I}

Listagem geral das espécies de pteridófitas registradas na Área de Pesquisa do Guamá (APEG), dentro das reservas Aurá (mata de várzea), Mocambo (mata de terra firme) e Catu (mata de igapó). Belém, PA.

\begin{tabular}{|c|c|c|c|c|}
\hline \multirow[t]{2}{*}{ No. } & \multirow[t]{2}{*}{ Família/Espécie } & \multicolumn{3}{|c|}{ Ambientes } \\
\hline & & Mocambo & Catu & Aurá \\
\hline \multicolumn{5}{|c|}{ I. Marattiaceae } \\
\hline 1 & Danaea simplicifolia Rudge & $\mathrm{x}$ & & $x$ \\
\hline \multicolumn{5}{|c|}{ II. Hymenophyllaceae } \\
\hline 2 & Hymenophyllum polyanthos (Sw.)Sw. & $\mathrm{x}$ & $\mathrm{x}$ & $\mathrm{x}$ \\
\hline 3 & Hymenophyllum magellanicum Willd.** & & & $x$ \\
\hline 4 & Hymenophyllum sp. & & $x$ & \\
\hline 5 & Trchomanes vitaria D.C. & $\mathrm{x}$ & $x$ & $\mathrm{x}$ \\
\hline 6 & Trichomanes pinnatum Hedw. & $x$ & & \\
\hline 7 & Trichomanes repens Sw. + & $x$ & & \\
\hline \multicolumn{5}{|c|}{ III. Metaxyaceae } \\
\hline 8 & Metaxya rostrata (H.B.K.) Presl & & & $x$ \\
\hline
\end{tabular}




\section{ACTA AMAZONICA}

COMPOSIÇÃO FLORÍSTICA E ABUNDÂNCIA DE PTERIDÓFITAS EM TRÊS AMBIENTES DA BACIA DO RIO GUAMÁ, BELÉM, PARÁ.
No.

\section{Cyatheaceae}

9

10

V. Pteridaceae

11

12

13

14

15

VI. Vitariaceae

16

17

VII. Dennstaediaceae

18

19

VIII. Dryopteridaceae

20

21

22

23

24

25

26

27

28

29

IX. Aspleniaceae

30

X. Davalliaceae

31

32

33

34

35

36

37

XI. Selaginellaceae

38

39
Família/Espécie

Sphaeropteris hirsuta (Desv.)Tryon

Sphaeropteris cyatheoides (Desv.)Windisch ++

Adiantum petiolatum Desv.

Adiantum serrato-dentatum Willd.

Adiantum cayennense Willd.

Adiantum fructuosum Spreng***

Adiantum terminatum Kze.

Hecistopteris pumila (Spr.) J.Sm.

Antrophyum cajenense (Desv.) Spr.

Lindsaea lancea var. lancea (L.) Bedd.

Lindsaea lancea var. falcata (Drand.) Rosenst.

Triplophyllum funestum (Kunze) Holttum

Tectaria incisa Cav.

Dryopteris sp.+

Stigmatopteris heterocarpa (Feé) Rosensit. **

Stigmatopteris sp.

Polybotrya caudata Kze.

Polybotrya suberecta (Baker) C.Chr.*

Lomariopsis japurensis (Mart.) J.Sm.***

Elaphoglossum discolor (Kuhn) C.Chr.

Elaphoglossum cf. plicatum (Cav.) C.Chr. ${ }^{* * *}$

Asplenium serratum L.

Polypodium ciliatum Willd.+

Dicranoglossum desvauxii (Kl.) Proctor

Microgramma lindbergii (Mett.) Sota**

Microgramma tecta (Kaulf.) Alston***

Microgramma lycopodioides (L.) Copel.

Campyloneurum repens (Aubl.) Prest.***

Grammitis serrulata (Sw.) Sw.

Selaginella amazonica Spring

Selaginella stellata Spring+

\begin{tabular}{c} 
Ambientes \\
\hline Mocambo Catu Aurá
\end{tabular}

$X$

$X$

$x \quad x$

$x \quad x$

$x$

$\mathrm{X}$

$\begin{array}{lll}x & x & x \\ x & x\end{array}$

$X \quad X \quad X$

$X$

$x \quad x \quad x$

$x \quad x \quad x$

$X$

$x$

$x-x$

$x$

$x \quad x$

$x \quad x$

$\mathrm{X}$

$X$

$X$

$X$

X

$\begin{array}{lll} & x & \\ & x & x \\ X & x & x\end{array}$

X $\quad X$

$x$

X

* Nova referência para o Brasil ** Nova referência para a Região Norte *** Nova referência para o Estado do Pará

+ Citação de literatura ++Referência do Herbário Murça Pires (MG)

RECEBIDO EM 10/09/2002

ACEITO EM 28/11/2003 